\title{
LONTARAK LATOA SALAH SATU SUMBER INFORMASI TENTANG HUKUM BAGI MASYARAKAT BUGIS
}

\section{Jumadi}

Universitas Islam Negeri (UIN) Makassar

Email : Jumadirahman263@yahoo.com

\begin{abstract}
Especial source of the august value complete in lontarak. Thinker of is socalled in it lay open life image and ideas owning philosophy value which with quality. If that idea arrive and known by next generation of course will penetrate life of society, even come up with this recent epoch. Value having the character of that moral for example have been laid open by To Riolo (former sage), that four kinds of deed him both for having precedence over. First, thinking of all good utterance and wise deed of everybody. second, Searching way out of idea concept swiftly and precisely, that intention which is wrong to be barricaded to be realized by goodness in words and also in behaviour. Third, bearing with when befalled by accident, but gaze to find its solution. Fourth, soft in saying word so that faced always in a condition peace.
\end{abstract}

Keyword : Lontarak, Bugis

\begin{abstract}
Abstrak
Sumber utama nilai luhur tersebut lengkap dalam lontarak. Pemikir yang disebut di dalamnya mengungkapkan ide-ide dan citra kehidupan yang memiliki nilai filsafat yang berkualitas. Apabila ide itu tiba dan diketahui oleh generasi berikutnya tentu akan menembus kehidupan masyarakat, bahkan sampai pada zaman mutakhir ini. Nilai yang bersifat moral itu antara lain telah diungkapkan oleh To Riolo (orang bijaksana dahulu), bahwa empat macamnya perbuatan baik yang harus didahulukan. Pertama, memikirkan semua ucapan baik dan perbuatan bijak dari semua orang. Kedua, Mencari jalan keluar dari konsep pemikiran dengan cepat dan tepat, bahwa niat yang salah dibendung untuk diwujudkan baik dalam kata-kata maupun dalam tingkah laku. Ketiga, bersabar bila ditimpa musibah, namun merenung untuk menemukan solusinya. Keempat, berlemahlembut dalam bertutur kata agar yang dihadapi selalu dalam kondisi damai.
\end{abstract}

Kata kunci : Lontarak, Bugis

Jurisprudentie | Volume 5 Nomor 1 Juni 2018 


\section{PENDAHULUAN}

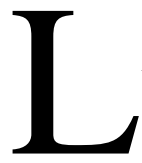

atoa, adalah nama dari salah satu jenis Lontarak dalam perpustakaan berbahasa Bugis di Sulawesi Selatan. Pencatatan Latoa sebagai Lontarak, diduga berlansung pada zaman Raja Bone (Arungpone) ke 7 yang bernama Latenrirawe Bongkannge (1560-1578) bertahta di Tana Bone. Raja memiliki cerdas cendekia sebagai penasihat bernama La Mellong, seorang anak Matoa di sebuah desa bernama Laliddo (ng) dalam wanua (negeri) Cina di Tana Bone. La Mellong inilah pada masa tuanya terkenal dengan gelar ((sebutan) Kajao Laliddo yang berarti orang bijakasna dari Laliddo atau orang tua (Tokoh) berasal dari Laliddo.

Menurut anggapan umum orang-orang Bugis (khususnya di daerah Bone), Latoa berisi pembicaraan antara Kajao Laliddo dengan Arungpone. Anggapan umum ini tidaklah seluruhnya benar, namun tidak pula dapat dipersalahkan. Menurut bahasan yang lebih terinci, dapat dikatakan bahwa Latoa adalah Lontarak yang dalam kepustakaan Bugis berisi kumpulan ucapan-ucapan, petuah dari rajaraja dan orang-orang bijaksana Bugis-Makassar dari zaman dahulu (termasuk zaman Kajao Laliddo). Petuah tersebut, mengenai hal-hal yang berkaitan dengan kewajiban-kewajiban raja kepada rakyatnya dan sebaliknya kewajiban rakyat kepada rajanya, Latoa dijadikan sebagai tuntunan bagi penguasa terutama dalam menjalankan pemerintahan dan melaksanakan peradilan.

Menurut Matthes, Latoa bagi kalangan Bugis dapat dipersamakan dengan Rapang bagi orang-orang Makassar. Seperti yang termuat dalam M.Chr. pada halaman 456 sampai dengan 460 dan halaman 471 sampai dengan $480 .^{1}$

Latoa yang tersebar dalam kepustakaan ilmiah dan telah menjadi kajian ilmiah adalah Latoa yang termuat dalam Bouginesche Chrestomatie atas usaha B.F. Matthes, dicetak dalam tahun 1872. Latoa dalam Bouginesche Chrestomatie. itu sebagian terbesarnya adalah salinan Lontarak tulisan tangan (Handshrift-HS) berasal dari Arung Pancana Tua La Paga' Lipue Colli’ Pujie. Sebahagian besar (tidak seluruhnya) isinya dimuat dalam Bouginesche Chrestomatie tersebut. Tersimpan dengan cermat dalam perpustakaan Legatum Warnerianum, Rijks Universiteit, Leiden Belanda. Tercatat dalam Katalogus (Kort-verslag B.F. Matthes, 1875) dengan nomor daftar HS $120 .^{2}$

Menurut beberapa orang Bugis terkemuka, HS 120 tersebut diperkirakan adalah turunan atau salinan ketiga dari Lontarak asli yang tidak diketahui lagi

\footnotetext{
${ }^{1}$ B.F. Matthes, Boeginesche Chrestomatie, II, Het Nederlandsch Gouvernement, Amsterdam, 1872, h.109.
}

${ }^{2}$ Ibid, h.110 
keberadaannya. Dalam HS 120 itu, nyata telah diadaptasikan dengan unsur-unsur Islam dan pengaruh-pengaruh kekuasaan Belanda. Terhadap HS. 120 itu Matthes (1872: 109) menyatakan bahwa, sebahagian besar dari HS. 120 itu dimuat dalam Bouginesche Chrestomatie. Oleh karena itu dengan singkat dapat disebut, bagianbagian isi HS 120 yang tidak termuat dalam Bouginesche Chrestomatie terdiri atas penggalan-penggalan ucapan dari : (1). Puang ri Maggalatung; (2) Kajao Laliddo; (3) TorioloE; (4). Karaeng Matoae; Tumenanga ri Ujung Tana; Karaenta Tomammenang ri Taennge; Karaenta Sumanna' dan Addatuatta Matinroe ri Pammatingang; (5) dua orang Gowa terkemuka lainnya, masing-masing Tuminanga ri Lakiung dan Karaeng Matoae; (6) Arung Bila; (7) Matinroe ri Palla'na; (8) Matinroe ri Nagauleng; (9) To Panritae dan (10) I Tuang ri Dima.

Penggalan-penggalan atau ucapan-ucapan yang tidak disebut dalam Bouginesche Chrestomatie ternyata sebahagiannya adalah pengulanganpengulangan masalah yang dimuat sesudahnya. Bagi kalangan tokoh Makassar beranggapan bahwa dengan sengaja Matthes tidak memuat (meninggalkan) petuah-petuah (amanah) orang terkemuka dari Makassar (Gowa) untuk menimbulkan kesan bahwa Latoa adalah semata-mata milik (rohaniah) orang Bugis.

Dalam Kort-Verslag Matthes tahun 1875 ditunjukkan adanya satu Koleksi Naskah Lontarak bertulisan tangan (HS) Bugis-Makassar yang semuanya berjumlah 203 naskah. Semua naskah itu masih tersimpan dengan cermat pada perpustakaan Legatum Warnerianum, Universitas Leiden Belanda.

Diantara naskah-naskah Lontarak HS itu, terdapat 8 buah yang memuat salinan-salinan atau pengggalan-penggalan Latoa. Kedelapan penggalan yang dimaksud telah tercatat dengan nomor katalogus, masing-masing dengan nomor: (1) HS 100; (2) HS 106; (3) HS 120; (4) 121; (5) HS122; (6) HS 123; (7) HS 125; dan (8) HS 127. ${ }^{3}$

Menurut catatan A. Dence pada Lembaga Kebudayaan Indonesia, bahwa terdapat juga koleksi naskah Lontarak (HS) Bugis-Makassar sebanyak 33 buah naskah, diantaranya ada yang memuat penggalan-penggalan Latoa (HS.Vt.125; HS.Vt.132; dan HS.Vt. 133). ${ }^{4}$

Hal ini dikemukakan untuk menjelaskan bahwa Latoa sebagai satu jenis Lontarak Sulawesi Selatan, dimana dalam kandungannya terdapat berbagai versi. Setiap versi berorientasi pada keperluan masing-masing negeri yang menerbitkan atau menuliskannya dalam Lontarak negeri bersangkutan. Misalnya terdapat jenis

\footnotetext{
${ }^{3}$ Ibid.

${ }^{4}$ Ibid.
} 
Lontarak versi Wajo, Soppeng Luwu dan lain-lain, disesuaikan dengan keperluan peradaban masing-masing ketika itu. Akan tetapi Latoa versi Bone, kelihatannya lebih dominan dan memuat pengetahuan umum yang lebih luas, khususnya berkaitan dengam tokoh terkuat di dalamnya, misalnya La Mellong To Sualle, alias Kajao Laliddo, penasihat dan orang bojaksana tana Bone dalam Abad ke-16.

\section{PEMBAHASAN}

Latoa sebagai salah satu diantara sekian banyak Lontarak (rontal) atau manuskrip orang Bugis-Makassar, memiliki arti khusus, karena telah dijadikan Rapang (pedoman) bagi orang Bugis-Makassar dalam rangka kepemimpinan masyarakat dan kekuasaan. Latoa telah berperan sebagai pedoman bagi seseorang raja dalam menjalankan kekuasaan memerintah dan telah menjadi penuntun bagi rakyat untuk menentukan sikap terhadap bentuk kekuasaan yang diikuti atau tidak sudi ditaatinya.

Sebagai rapang, Latoa mengandung kalimat-kalimat hikmah, buah-buah pikiran, petunjuk-petunjuk, bahkan terdapat doktrin-doktrin raja dan orang-orang bijaksana pada masa lalu (sekitar abad ke 14 sampai dengan abad ke 16) di kalangan Bugis-Makassar.

Postulat-postulat negara dan masyarakat telah dilukiskan di dalam Latoa, tersimpul dalam apa yang disebut dengan Pangadereng. Oleh karena telah menjadi wujud kebudayaan, maka di dalamnya memiliki lima aspek penting yaitu : (1) adek (customs); (2) bicara (peradilan); (3) rapang (kaidah yang telah terjadi); (4) wari (tata tertib kerukunan, kekeluargaan dan kemaslahatan); dan (5) sarak (syariat Islam). Aspek kelima ini diadaptasi masuk ke dalam pangadereng. Dengan kata lain setelah Islam diterima sebagai agama yang mayoritas dianut oleh rakyat.

a. Adek. Adalah bagian komponen pangadereng yang mengatur pelaksanaan sistem norma dan aturan-aturan hidup dalam masyarakat. Kata adek sukar dibedakan dengan adat yang sudah meresap ke dalam kebudayan bangsa Indonesia atas pengaruh Islam. Adat dari kata adatun (Bahasa Arab) telah dibedakan baik isi maupun aplikasinya dengan pengertian adek. Jadi adek adalah, pernyataan atau perwujudan segenap tata tertib dalam bersikap dan bertindak dalam kehidupan masyarakat dan kebudayaan. Bilamana adek sebagai pranata sosial, maka ia adalah pola-pola ideal dalam bentuk dan suasananya yang beraneka ragam, berfungsi menentukan pola-pola formal menurut urutan berlakunya serta sarana-sarana 
penunjangnya. Di dalam adek sebagai pranata sosial didapati adanya beberapa jenis, antara lain:

1. Adek puraonro, yaitu : norma yang sudah tetap dan sulit untuk didirubah;

2. Adek abiasang, yaitu norma kebiasaan; dan

3. Adek maraja, yaitu norma baru yang muncul dari hasil interaksi manusia dan perkembangan (pembangunan).

Ketiga jenis norma itu, terwujud dalam bicara, rapang dan wari. Adek menurut wawasan dan ruang lingkupnya bersifat preventif, memelihara stabilitas negara, pengamanan dari perbuatan jahat, mencegah perbuatan sewenang-wenang dari orang kuat (berkuasa) dan melindungi si miskin dan lemah.

b. Bicara. Adalah aturan yang menyangkut peradilan dalam arti luas. Peranan komponen bicara ini lebih bersifat repressif, menyelesaikan sengketa dan berorientasi pada harmonisasi. Bicara dalam arti peradilan senantiasa berpijak pada keadaan objektif, memutuskan perkara seadil-adilnya, agar keresahan dan sengketa tidak merajalela. Bicara sebagai aturan yang sepenuhnya menjaga tegaknya keadilan.

c. Wari. Adalah aturan yang mengatur tentang batas-batas, pembeda antara satu dengan lainnya, suatu perbuatan yang selektif, menata dan menertibkan. Ruang lingkupnya, berada pada penataan batasbatas pelapisan sosial, protokolistis, aturan hak dan kewajiban setiap orang menurut aturan status sosial, posisi sosial dan menurut fungsi tertentu dari jabatan negara.

d. Rapang. Adalah aturan yang ditetapkan setelah membandingkan keputusan-keputusan yang lalu atau membandingkan dengan keputusan adat di negeri tetangga. Rapang dalam arti leksikal adalah contoh. Misal, perumpamaan dan kias. Rapang sebagai salah satu komponen pangadereng, maka untuk mengambil keputusan dalam peristiwa adek, tidaklah harus membuat landasan-landasan baru, bila sebelumnya itu tidak pernah terjadi peristiwa seperti itu. Ketentuan-ketentuan mengenai peristiwa lalu , menjadi pedoman peristiwa sekarang, itulah rapang. Dalam hal peradilan (bicara), rapang dapat diidentikkan dengan jurisprudensi. Rapang juga berperan memelihara stabilitas dan kesinambungan kepercayaan pada pangaderenng. 
e. Sarak. Setelah ajaran Islam masuk dan menjadi agama komunitas bugis, keempat komponen pengadereng tersebut ditambah satu komponen lagi yang sarak kira-kira berlangsung sekitar abad ke-17.

Mengenai adek, bicara, wari dan rapang, telah dijelaskan oleh Kajao Laliddo berkaitan dengan perbuatan-perbuatan atau tindakan-tindakan yang menjadi dasar pemunculannya. Semua tindakan hukum yang dilakukan oleh anggota masyarakat akan termasuk dalam empat kategori tersebut. Peristiwaperistiwa hukum terjadi oleh adanya perbuatan-perbuatan seperti berikut ${ }^{5}$ :

a. Adek terjadi karena adanya perbuatan yang mempertentangkan (Bugis: mappasisala). Segala macam perbuatan yang berselisih, bersengketa atau sejenisnya. Semua itu diselesaikan menurut ketentuan adek yang diikuti pula dengan sanksi-sanksinya, menyertakan diri dalam usaha-usaha pencegahan.

b. Bicara terjadi karena adanya perbuatan yang saling mengadu kekuatan dan pembicaraan yang saling mengatasi. Perbuatan anggota masyarakat seperti demikian, dimasukkan dalam ketentuan-ketentuan bicara dalam arti peradilan. Usaha-usaha operasionalnya lebih banyak ditujukan kepada tindakan repressif yang sangat konsisten. Peristiwa hukum demikian dilakukan oleh pejabat adek dalam peradilan.

c. Wari terjadi karena adanya perbuatan yang memperbedakan atau dengan kata lain perbuatan yang membedakan antara hubungan yang satu dengan lainnya, membedakan hak dan kewajiban seseorang sesuai fungsi, status dan posisinya dalam masyarakat. Berguna untuk menciptakan ketertiban masyarakat dan mencegah terjadi keprihatinan sosial. Pejabat adek yang bertugas membedakan hak dan kewajiban, status, pelapisan individu dalam masyarakat termasuk fungsi-fungsinya, harus mengikuti ketentuanketentuan wari.

d. Rapang terjadi karena adanya perbuatan yang mempersamakan atau kekuatan yang akan diambil itu berdasarkan persamaan dari suatu peristiwa yang pernah terjadi (lebih dahulu muncul sebagai perbuatan hukum). Keputusan yang mempersamakan tersebut masuk ke dalam ketentuan rapang.

${ }^{5}$ A. Palloge, Lontara Latoa, Sekelumit Pandangan dan Pembahasan kebudayaan Bone, (Makalah), 1986, h. 1-9. 
Keempat macam perbuatan tersebut ditemukan dalam berbagai aspek ideal pangadereng dan menyatakan diri dalam keseluruhan sistem-sistem yang mengikat serta menjadi pedoman bagi individu dalam masyarakat. Semua peristiwa dan perbuatan hukum yang ditimbulkan oleh anggota masyarakat akan dikategorikan ke dalam keempat macam komponen pangdereng di atas. Perbuatan-perbuatan hukum diselesaikan dikuti dengan sanksi-sanksi dari mana perbuatan dan peristiwa itu termasuk.

Pangadereng dengan lima aspeknya itu memperoleh kekuatan gerak dan dorongan dari apa yang disebut sirik. Konsepsi sirik seperti dinyatakan dalam pangadereng dapat ditanggapi sebagai etos budaya yang menjadi sumber motivasi yang amat kuat dalam menetapkan pola-pola prilaku dan mewarnai keputusankeputusan, tindakan-tindakan atau perbuatan orang Bugis-Makassar. Konsep sirik menghadapi hampir seluruh masalah dalam kehidupan masyarakat BugisMakassar.

Melalui pengkajian mendalam dari Latoa dapat direkonstruksi bebarapa kerajaan besar (utama) Bugis-Makassar dan kerajaan keluarga lainnya pada masa lampau. Seperti Bone, Gowa, Luwu, Wajo, Soppeng. Kerajaan itu telah dibangun berdasakan lima aspek pangadereng. Rekonstrukasi itu dapat pula meliputi berbagai pranata dan lembaga kekuasaan. Aspek tersebut ternyata masih memainkan peranan dalam kehidupan masyarakat Bugis-Makassar sampai pada zaman mutakhir ini, walaupun sudah semakin samar. Pengaruh itu terutama meliputi bentuk-bentuk sikap hidup seperti: (1) sikap spontanitas yang tinggi, (2) struktur dan stratifikasi sosial yang dipertahankan dengan teliti, (3) prilaku dan kebiasaan apriori, dan (4) sikap kekeluargaan yang tinggi dan keras.

Latoa dan Lontarak Bugis-Makassar lainnya, juga dapat menjadi sumber informasi mengenai keadaan sekitrar abad ke-16 dan sesudahnya sampai abad ke17. Sejak permulaan abad ke-16, kerajaan-kerajaan orang Bugis-Makassar, lambat laun kehilangan kemerdekaan dan kedaulatannya. Mereka mulai hidup saling perang antara satu dengan lainnya, sampai pada kedatangan dan penaklukan total oleh Belanda pada tahun 1906. Dalam waktu yang tidak kurang dari 3 abad lamanya orang Bugis-Makassar berada dalam kondisi yang tak menyenangkan, kacau tak berkesudahan, dan terisolasi dari perkembangan yang terjadi di bagian lain dari kepulauan nusantara. Keadaan tidak stabil itu terjadi sampai pada kemerdekaan Republik Indonesia, bahkan masih terjadi sekitar sepuluh tahun sesudahnya.

Dalam keadaan yang demikian kacau itu, ditemukan informasinya di dalam Latoa. Di dalamnya ditemukan pula pedoman-pedoman yang memberi arah bagi seseorang untuk menentukan dan mencari penyelesaian. Pedoman 
tersebut berkelanjutan dan berakibat pada prilaku sebahagian besar orang BugisMakassar sampai pada hari ini. Bentuk prilaku yang dimaksud adalah :

1. Bercuriga kepada sesuatu yang baru sedang mendatangi;

2. Bersikap apriori terhadap sesuatu yang berlawanan dengan perasaan keadilan;

3. Cepat mengambil suatu keputusan atau tindakan terhadap sesuatu yang menyangkut martabat atau harga diri (sirik), pribadi atau kaumnya.

Apabila didalami kandungan dari makna etik yang tertuang di dalam Latoa ini, maka untuk masa kinipun, terasa masih memungkinkan untuk dipergunakan sebagai pedoman untuk mendekati dan menuntun orang-orang Bugis-Makassar menghadapi pembangunan dan ketahanan integritas bangsa Indonesia.

\section{PENUTUP}

Bertolak dari inti ajaran pangadereng ini, tata kehidupan dan ketatanegaraan Bugis berlangsung dengan mengedepankan kualitas moral. Kenyataannya mampu menjadi pilar kokoh menegakkan sirik dan ade pura onro pada masanya. Menempatkan hak-hak dasar manusia untuk dijalankan melalui contoh kebijakan raja. Hak azasi yang dihargai disandarkan pada keyakinan akan makna kemanusiaan, baik dalam bertingkah laku maupun berbangsa dalam negeri. Meskipun pada awalnya sangat sederhana rumusannya, namun dari generasi ke genarasi mengalami perbaikan dan sampai pada kondisi adaptasi dengan idiologi yang berpengaruh. Hak, hukum, sistem pemerintahan dan partisipasi dalam bermasyarakat, kemudian bersesuian dengan idiologi Islam dan selanjutnya membentuk sistem baru, tanpa menghilangkan nilai-nilai luhur budaya yang bersifat azasi dan universal. 


\section{DAFTAR PUSTAKA}

Ali Alatas, Nilai Kebudayaan dan Disiplin Nasional, Sirik, Seminar Kebudayaan Nasional, Pengkajian Melayu, Universitas Malaya, Kuala Lumpur, 1963.

Andaya L.A.A., Village Perception of Arung Palakka And The Makassar War, 1665-1669, 1979.

Andi Muing MG., Bugis Makassar dan Prinsip Sirik Na Pacce, Yayasan Makassar Press, 1989.

Andi Zainal Abidin Farid, Persepsi Orang Bugis Makassar Tentang Hukum, Negara dan Dunia Luar, Alumni, Bandung, 1983.

Pandangan Orang Sulawesi Selatan Menurut Lontarak yang Dapat Dijadikan Penggerak Pembangunan Daerah, (Makalah) 1986.

Wajo Pada Abad XV-XVI (Suatu Penggalian Sejarah Terpendam Sulawesi Selatan dari Lontarak), Alumni, Bandung, 1985.

Indra Chanra, Kerajaan Bugis Bone Dalam Konteks Kerajaan Tellumpoccoe, (Makalah), 1986.

Koentjaraningrat, Kebudayaan, Mentalitas dan Pembangunan, PT. Gramedia, Amsterdam, 1947. 1976.

Mattulada, Lontarak La Toa (Sumber Informasi Tentang Kebudayaan Di Sulawesi Selatan), Makalah, 1986.

Mustamin Dg. Matutu, Selayang Pandang (Tentang) Perkembangan Tipe-tipe Negara Modern, Pidato, Lustrum IV, Fakultas Hukum Unhas, Ujung Pandang, 1972.

Shelly Errington, Sirik, Darah dan Kekuasaan Politik Kerajaan Luwuk Zaman Dahulu, Bingkisan Budaya Sulawesi Selatan, Th.. I Nomor 2 Yayasan Kebudayaan Sulawesi Selatan, 1977.

V.E. Kron, Problemen der Makassar-Buginese Semenleving, BKI, CVIII, 1952. 